\title{
Pictogram, Powerful Information Tool for People
}

\author{
George ADÎR*, Victor ADîR, Nicoleta-Elisabeta PASCU
}

\begin{abstract}
Pictograms can be found all around the world, namely in: business centres, shopping malls, network communication, airports, hospitals, museums, libraries, universities and schools, gyms and skating rink, zoo etc. Also, pictograms could be seen inside the city maps and in an attached legend. In this paper we want to underline the great importance of pictograms everywhere and to introduce, in our opinion, some interesting proposals for pictograms.
\end{abstract}

Keywords: allow; graphical identity; pictogram; warn

\section{INTRODUCTION}

Achievement of a pictogram is not so easy. A pictogram has to inform, guide, allow, prohibit or warn depending on the situation. It is a drawing telling something but without words, ensuring a graphical identity. It has to be visible and accessible, clear and the message sent has to be completely understood by many people. The designer's expertise means so much in the achievement of pictograms. It cannot be conceived nowadays a world without pictograms.

\section{THE SIGNAGE SYSTEM CONCEPT}

The signage system is a set of graphic and visual representations, an integral concept founded by the graphic perception of the public, having signs, symbols, pictograms, adequate geometric shapes and colors [1]. It means that a signage system has to encode in good graphic drawings the needs of the public.

When a signage system will be designed, it has to take into consideration some aspects, namely:

- Kind and number of the necessary graphic representations.

- Location of symbols on signage panels.

- Kind of the geometric shapes used.

- Location of the signage panels.

- The meaning of each graphic representation; the designer will build a data base related to the message of every representation, to be sure of the correct interpretation of the sign/symbol.

- Kind of letters / figures / words and colors chosen for a rapid and effective visualization of information.

- The necessary tools to convey better the information.

Pictogram is integrated in the signage process, having its own features. A pictogram has to be easily identified and understood, clear and able to assure fast moving in a certain direction. Use of pictograms have many advantages:

- greater visibility of some warnings, for attracting much better the attention,

- more clear deal of warning messages for the people with less education or with view problems,

- faster interpretation and with greater accuracy, by comparison to the use of words,

- allow instant save of a message/danger.
A very interesting explanation for what means a pictogram we have found in [2]. This graphic representation is created by people (it is not a natural thing), to allow a clear and a very good communication, it passes away the borders of language and conveys something special to everybody. A designer creates a set of pictograms, not only one, because it is necessary to create a flow of signage into a representation (mall, hospital, university, airport etc). Now, there are special graphic languages using pictograms in different fields (e.g. is the special language of pictograms in car industry a lot of pictograms on the dashboard help to drive a car better and in safety. Or the pictograms for the Olimpic Games represent another language describing the sport disciplines. And there are more and more examples.

By using qualitative and quantitative techniques (applied on a representative sample of consumers) there are achieved pictograms used on different products (inside/on the products' package, enclosed in the safety rules delivered with the product, in advertising materials etc).

The pictograms can be used individually or together with complementary measures, being able to solve different problems caused by the cultural and linguistic plurality, avoiding in this way the need to display information in more foreign languages.

Pictograms have to be culturally neutral to be understood all over the world. An important step to design a set of pictograms is an analysis related to the interpretations of a drawing in different cultures. A short time for reception, processing, translation and action for the public is a challenge for the designer to create good and understanding representations.

A special category of pictograms are the road signs, graphic and visual language well understood around the planet. Some of these pictograms warn, some impose restrictions or bans and other transmit general information (gas station, restaurant, parking). Also, there are pictograms that compel to do a certain thing.

According to [2], there are three types of signs: iconic, symbolic and index. Iconic signs communicate an idea directly, by the connection existing between the object and its representation as "icon", having a strong impact against those who receive the message. The symbolic signs achieve connection symbol-significance and the index signs guide to the object. The symbols used to design pictograms must be graphically clear and they have to suggest with accuracy what they want to present. 
What is really important, it is the context of using graphic representations. The right pictogram in the right place. In his book [3], Henry Dreyfuss gives a very good example of using a pictogram. It is the word POISON written on a bottle in different languages.

But for someone who does not know these languages it is a great danger, because he may drink it. But if a drawing on the bottle represents a skull and bones, everyone knows what is the meaning: DANGER. That is a simple example, but very reallistic of Henry Dreyfuss as regards importance of using pictograms.

\section{AIRPORT SIGNAGE SYSTEM}

If someone arrives in an international airport, the lack of pictograms to guide everywhere (custom, check in, gates, restaurant, coffee shop, ATM, bank, rent a car, exchange point, elevators/escalators, meeting point, information desk, toilets etc) could be a big problem for anyone. By using pictograms everything will be easier, so, pictograms act as an international language. A correct use of a signage system is an internal security element which has to insure passengers' safety in an airport.

\section{INTERNATIONAL DEPARTURES \\ GROUND FLOOR GATES AREA 24-39}
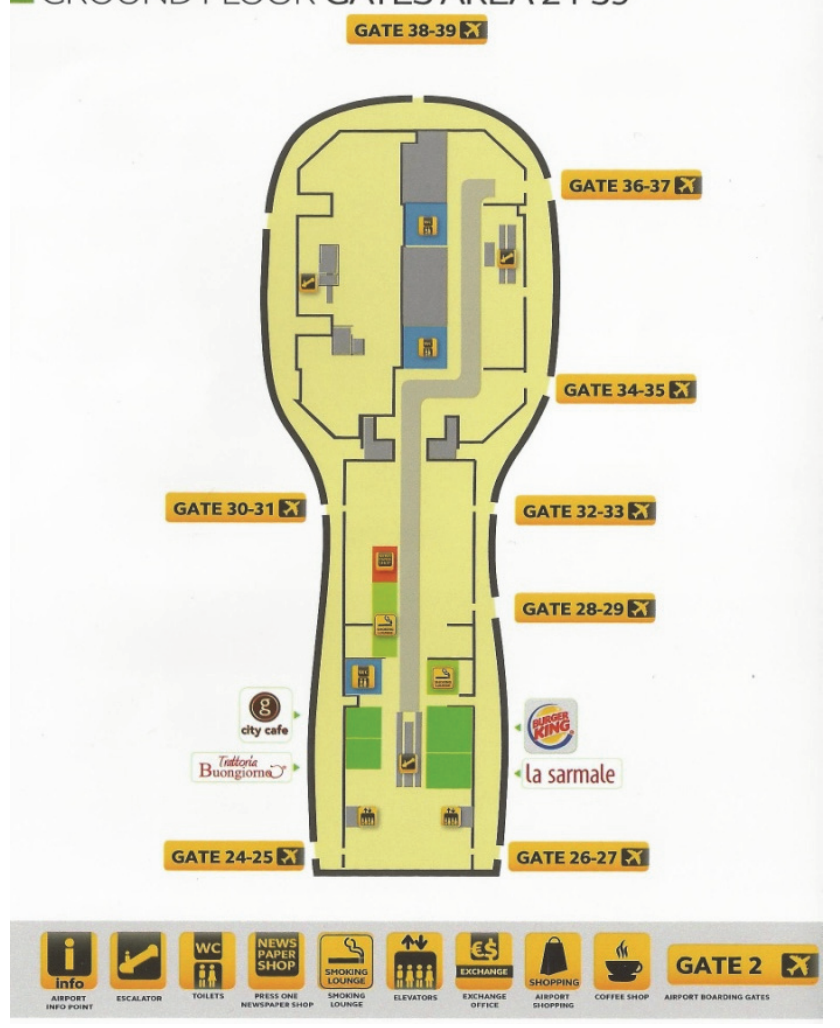

Figure 1 International departure (ground floor area)

Designing pictograms in an airport signage system is connected to the building architecture, distribution of halls, corridors where many people circulate, location of the signage panels, letters (font) and colors used. In airports there are two kinds of signage: "cold" (no lighting) and "hot" (illuminated).

The arrows and lines used in the airports have the goal to guide the people to different directions and locations. The lines could be thin/thick, to the left/right, up/down. For passengers, the designer creates a code of colors to support a clear understanding and rapid shifting on a passenger's trajectory.

In many airports we see black words written on a yellow fund. The yellow color draws the attention and creates a "lighting" panel, easy to be written.

For encoding, the airport signage system uses 3 types, namely:

- Colors encoding,

- Images encoding,

- Letters/figures encoding.

In Fig. 1 we present the area for international departures, ground floor, in an international airport ("Henri Coandă" International Airport, Otopeni, Romania) [4].

We have designed some pictograms [5] to underline their important role in our life (Fig. 2).
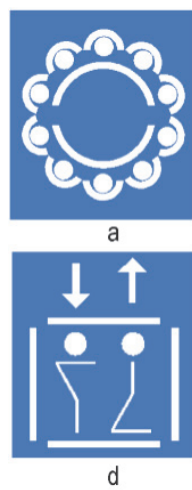
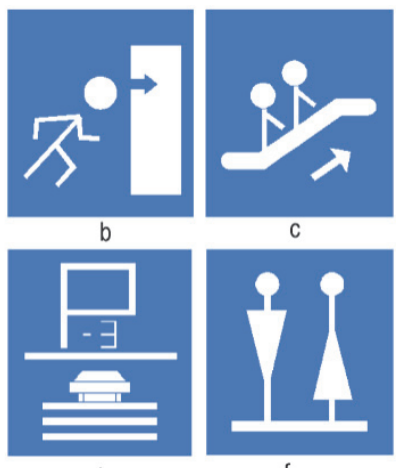

$f$

Figure 2 Different pictograms: a) meeting point; b) output; c) escalators; d) elevator; e) underground parking; f) toilets men/women

\section{SIGNAGE SYSTEM IN A HOSPITAL}

For a hospital, we have designed some pictograms [6] in Fig. 3.

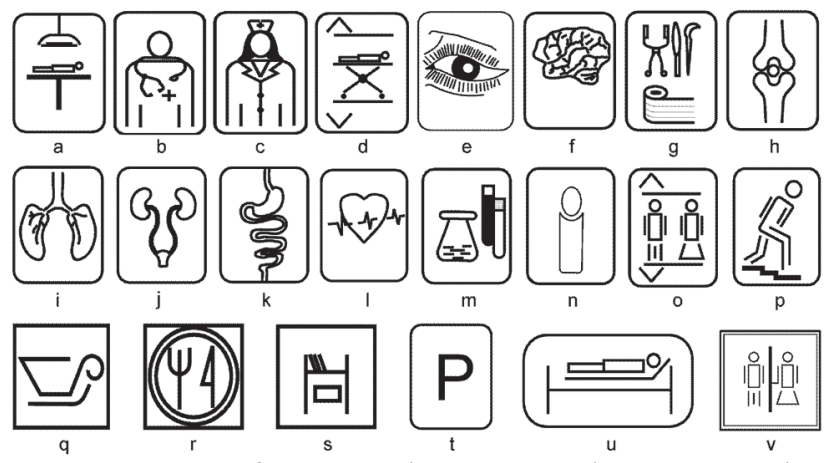

Figure 3 Pictograms for a hospital: a) operator block; b) doctors cabinet; c) nurses cabinet; d) stretcher elevator; e) ophthalmology; f) neurology; g) surgery; h) orthopaedics; i) pulmonology; j) urology; k) gastroenterology; l) cardiology; m) medical tests laboratory; $n$ ) information desk; o) elevator; $p$ ) stairs; q) coffee

shop; r) restaurant; s) book shop; t) parking; u) salon patients; v) toilets

We have integrated these pictograms in the sketch of a hospital, including parking area (Fig. 4).

\section{SIGNAGE SYSTEM IN A NATURE PARK}

We have designed a few pictograms for a nature park, in 2 variants.

For the variant 1 we propose to design pictograms inside green leaves (Fig. 5) and place them where is needed (Fig. 6).

In Variant 2 we have given up to leaves (Fig. 7). 

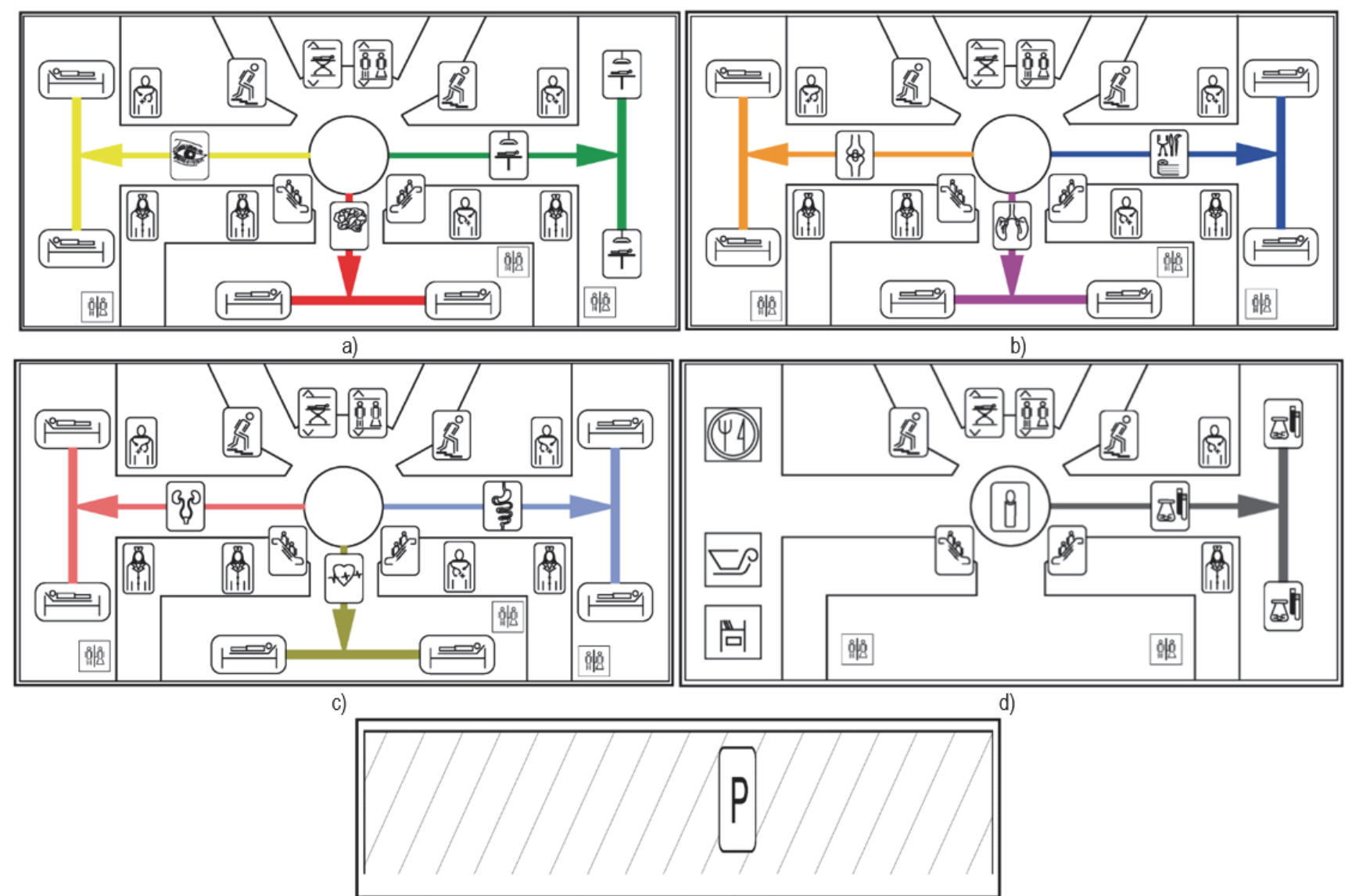

e)

Figure 4 Distribution of pictograms and travel routes in a hospital: a) Level 3: yellow line (Ophthalmology), green line (Operator block), red (Neurology); b) Level 2: brown line (Orthopaedics), blue (Surgery), purple line (Pulmonology); c) Level 1: pink line (Urology), light blue line (Gastroenterology), dark green line (Cardiology); d) Ground Level: grey (Medical tests laboratory); e) Parking Area.
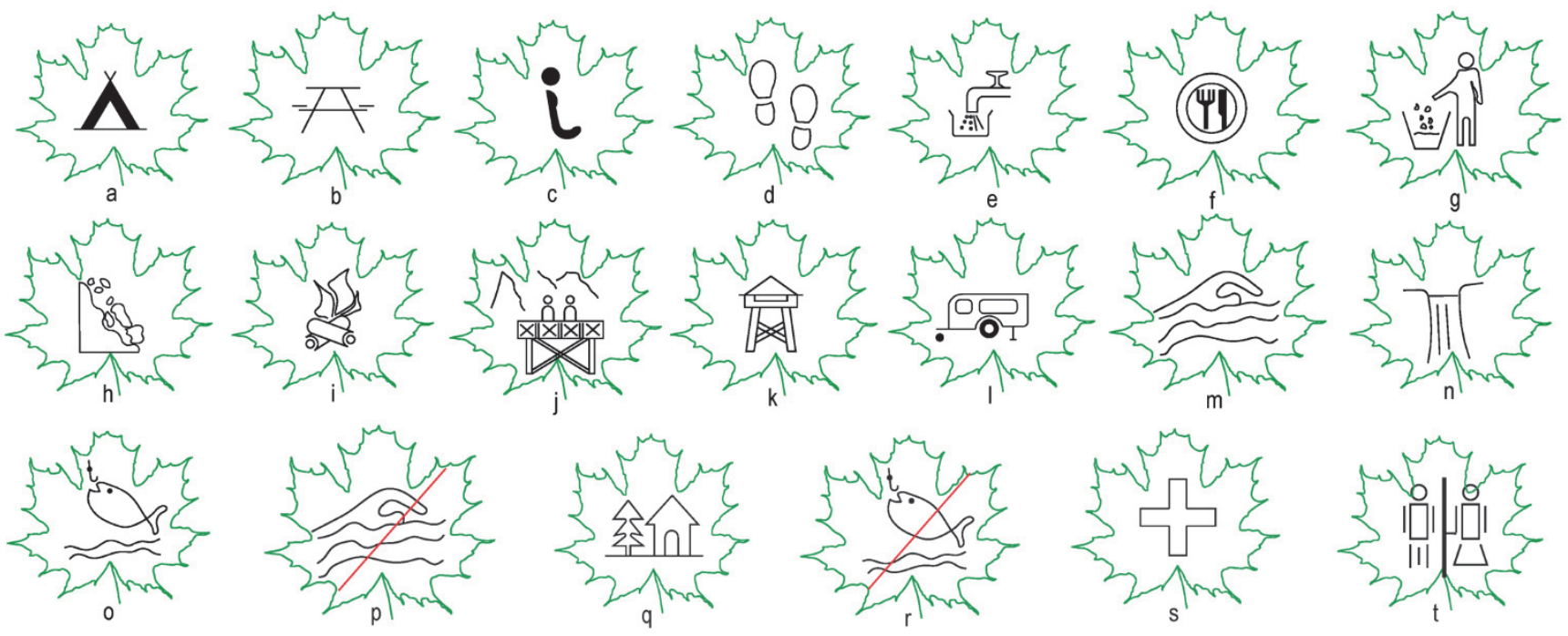

Figure 5 Pictograms inside green leaves: a) camping; b) picnic place; c) information point; d) trail route; e) drinking water; f) restaurant; g) cart trash; $h$ ) falling rocks; i) open fire place; j) landscape view place; k) observation tower; I) trailers camping; $m$ ) bathing allowed; $n$ ) cascade; 0 ) fishing allowed; $p$ ) bathing banned; q) entrance point; r) fishing banned; s) first aid point; t) toilets. 


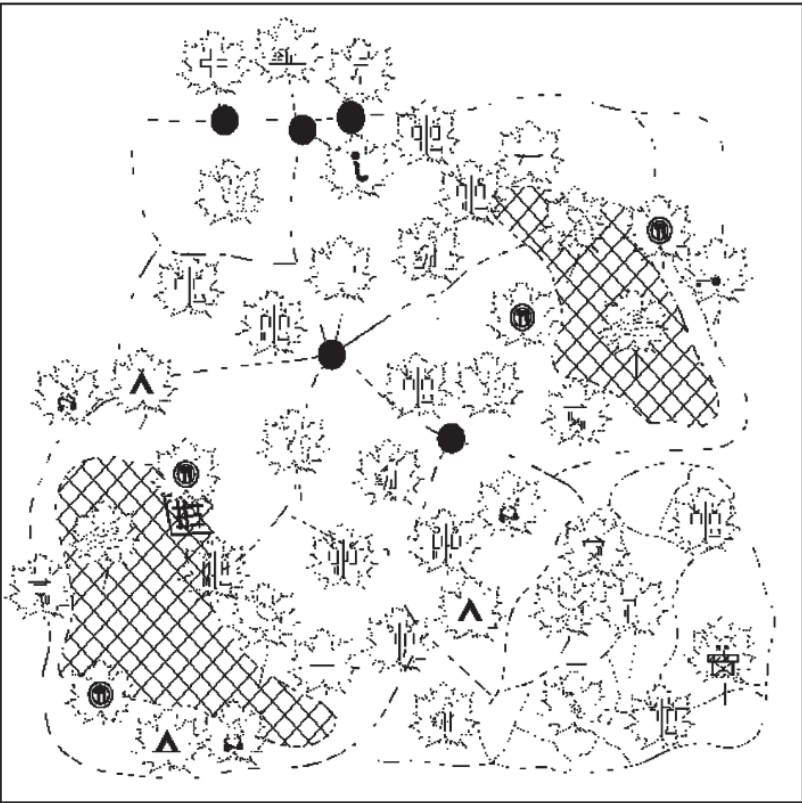

Figure 6 Nature park (Variant 1)

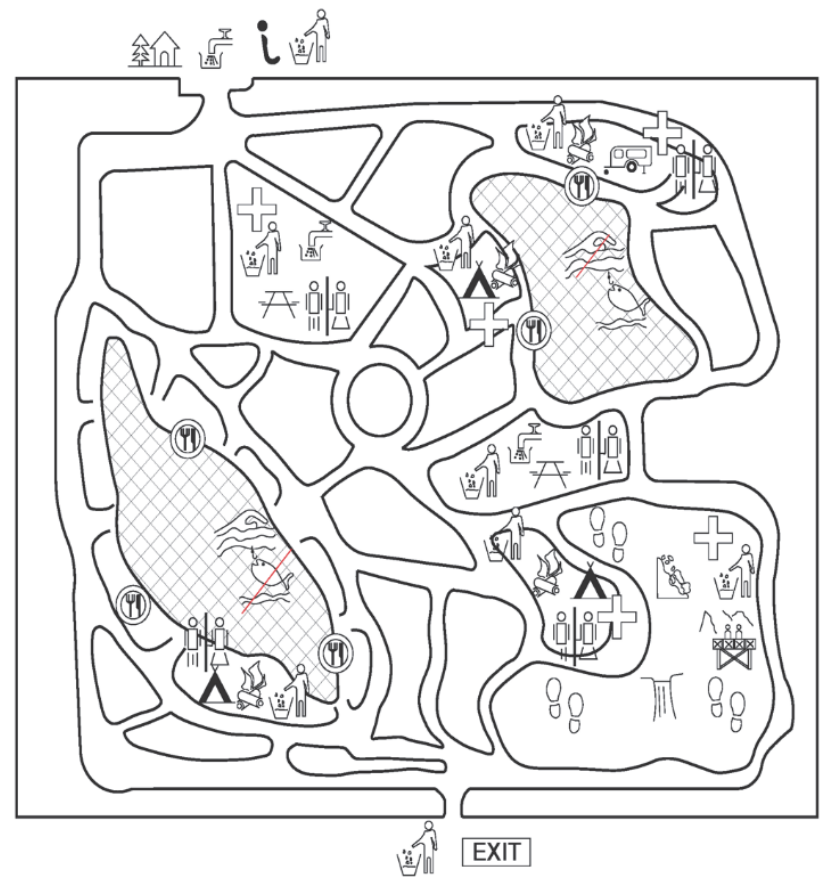

Figure 7 Nature park (Variant 2)

\section{CONCLUSIONS}

Without pictograms, as a universal language, it could be quite difficult for people to find the real routes in aiports, hospitals etc. Pictograms mean special communication, very useful for mankind, being of a real support for people of different nationalities to understand each other. Being convinced of their importance in the daily life, we have proposed, as examples of our work, new pictograms to be used in hospitals and nature parks.

\section{REFERENCES}

[1] Smitshuijzen, E. (2007). Signage Design Manual. Lars Müller Publisher, Baden.
[2] Rayan, A. \& Hubner, R. (2006). Pictograms, Icons \& Signs: A Guide to Information Graphics. Thames \&Hudson Ltd., London.

[3] Dreyfuss, H. (1984). Symbol Sourcebook. John Wiley \& Sons, Inc., New York.

[4] Adir, G., Adir, V, \& Zamfirescu, A. (2015). Comunicare, publicitate si negociere in afaceri. Editura Printech, Bucuresti.

[5] Adir, V., Pascu, N. E., \& Adir, G. (2014). Comunicare vizuala pringrafica. Editura Printech, Bucuresti.

[6] Adir, V., Pascu, N. E., \& Adir, G. (2016). Design de limbaj grafic-vizual. Editura Printech, Bucuresti.

\section{Contact information:}

George ADÎR, Assoc. Prof., PhD

(Corresponding author)

University POLITEHNICA of Bucharest,

Faculty of Engineering and Management of the Technological Systems,

Department of Theory of Mechanisms and Robots,

313 Splaiul Independenţei, sector 6, R0-060042, Romania

E-mail: georgeadir@yahoo.com

Victor ADÎR, Assoc. Prof., PhD

University POLITEHNICA of Bucharest,

Faculty of Aerospace Engineering,

Department of Descriptive Geometry and Graphical Engineering,

313 Splaiul Independenţei, sector 6, RO-060042, Romania

E-mail: victoradir@yahoo.com

Nicoleta-Elisabeta PASCU, Assoc. Prof., PhD

University POLITEHNICA of Bucharest,

Faculty of Aerospace Engineering,

Department of Descriptive Geometry and Graphical Engineering,

313 Splaiul Independenţei, sector 6, RO-060042, Romania

E-mail: nicoletaelisabeta_pascu@yahoo.ro 